\title{
Integração ou discriminação da pluralidade linguística na educação de línguas e pelas línguas: uma questão crucial entre ideologia, ética e didática $^{12}$
}

\section{Integration or discrimination of linguistic plurality in language education and the language: the crucial issue between ideology, ethics and didactics}

Philippe BLANCHET ${ }^{3}$

\author{
(Université Rennes 2 - França, \\ École Normale Supérieure (ENS) LSH d’Alger-Bouzaréah - Argélia)
}

\begin{abstract}
RESUMO: Este texto levanta a questão radical ${ }^{4}$ das implicações transversais da consideração ou, ao contrário, da rejeição da pluralidade linguística e cultural no ensino de línguas e, mais amplamente, na educação pelas línguas (COSTE, 2013). Ele apoia-se principalmente, e mais explicitamente, na questão linguística sem, no entanto, negligenciar, de maneira menos presente e menos explícita, a questão cultural e, sobretudo, intercultural. Este artigo, redigido por um especialista de dinâmicas sociolinguísticas e sociodidáticas francófonas, toma por exemplo prioritariamente o francês, mas a análise é certamente adaptável a outras línguas de difusão internacional, de escolarização e de status oficial estatal. Colocando-se em uma perspectiva sociodidática segundo a qual os fenômenos didáticos são e devem estar em continuidade direta com os fenômenos linguísticos, o presente texto parte de uma análise da pluralidade sociolinguística para, em seguida, obter dela uma conceitualização do que é uma competência linguística necessariamente sociolinguística. Ele confronta essas práticas sociolinguísticas heterogêneas e essas competências de utilização da pluralidade linguística no processo de elaboração e de ensino de línguas sem socialização e homogeneizadas sob a forma padrão artificialmente construído para fins políticos ideológicos. O artigo também analisa a divulgação e imposição consentida dessas línguas em termos de hegemonia e mostra em que isso produz discriminações negativas condenáveis por razões éticas e jurídicas, assim como fracassos socioeducativos. Ele propõe, por fim, princípios didáticos e orientações concretas de intervenção para integrar progressivamente e em profundidade a pluralidade linguística e cultural no ensino de línguas e em uma educação humanista pelas línguas.
\end{abstract}

PALAVRAS-CHAVE: Discriminação linguística. Educação linguística. Ideologia. didática.

ABSTRACT: In this text, the author deals with the issues of integrating or rejecting linguistic and cultural diversity in language teaching and more widely in education through languages. He presents a conception of (socio)linguistic competence elaborated out of an analysis of sociolinguistic diversity. He then compares, on the one hand, sociolinguistic practices and competences, to, on the other hand, the teaching process of desocialised and unified standard languages that were artificially elaborated to reach ideological political aims. He shows how teaching standard languages creates discriminations which are unacceptable both from an ethical and a legal points of view, and how it also creates social and educational failures. As a conclusion, he suggests pedagogical principles and

\footnotetext{
${ }^{1}$ Este texto se inspira em parte de Blanchet, Clerc, Rispail, 2014, "Reduzir a insegurança linguística dos alunos por meio de uma transposição didática da pluralidade sociolinguística", in Garnier, B. (coord.) Insécurité linguistique en éducation: approches sociologiques comparées des élèves issus du Maghreb, ELA-Revue de didactologie des langues-cultures n 175, p. 283-302., de BLANCHET (no prelo), O que é glotofobia? e, ainda, de Blanchet, (no prelo) “O 'domínio da língua' confrontado às práticas sociolinguísticas”, Revue Diversité n 176, Centre National de Documentation Pédagogique, p. 39-47.

${ }^{2}$ Texto foi traduzido para o português por Jaci Brasil Tonelli, mestranda do Programa de estudos linguísticos, literários e tradutológicos em Francês da USP. E-mail: alana.stardust@gmail.com

3 Prof. Dr. da Universidade de Rennes 2. E-mail: philippe.blanchet@univ-rennes2.fr

${ }^{4}$ No sentido "que vai à raiz dos problemas".
}

(C) Revista Moara, n.42, jul.-dez. 2014, Estudos Linguísticos. ISSN 2358-0658 (Impresso).

Programa de Pós-Graduação em Letras / Universidade Federal do Pará. Todos os direitos reservados 
pragmatic actions that could progressively and deeply integrate linguistic and cultural diversity into language teaching and a humanist education through languages.

KEY-WORDS : Ideology. Linguistic discrimination. Language education. Language teaching.

\section{Práticas sociais e pluralidade linguística: o exemplo do francês}

De um ponto de vista sociolinguístico (BLANCHET, 2012; BLANCHET, CALVET, ROBILLARD, 2007), o estudo das práticas linguísticas mostra que o mundo linguístico não é constituído de línguas estáveis preexistentes às práticas que as fariam variar ao colocá-las em uso, mas, sim, de um continuum de práticas sociais diversificadas e misturadas, sempre inovadoras, a partir das quais são construídas, por abstração e limitação, as línguas. Essas são categorizações, antes de tudo, sociopolíticas (existindo com finalidade principalmente comunitária, que são chamadas de "nações", "etnias" ou outros grupos sociais) e, às vezes, na continuação desta primeira categorização, são consideradas construções tecnolinguísticas homogeneizantes, marginais em relação aos usos efetivos, "inventadas por gramáticos e outros linguistas", para retomar uma formulação de Didier de Robillard (2008) e o título impressionante da obra de Louis-Jean Calvet (2004).

Assim, por exemplo, quando o francês foi amplamente difundido como língua falada em diversas partes da França e do mundo (essencialmente entre os séculos XIX e $\mathrm{XX}$ ), as populações que o adotaram espontaneamente o adaptaram as suas necessidades, hábitos, plurilinguismos, culturas e contextos. Elas se apoiaram, sobretudo, nos cruzamentos com as línguas que elas falavam previamente e que elas continuaram a falar paralelamente (os estudos sobre esse assunto são numerosos; para sínteses, consultar ROBILLARD, BENIAMINO, 1993, 1995; COLLECTIF, 2001; BAVOUX et coll., 2008). Desta forma, o francês se tornou uma língua efetivamente "viva", socializada, portanto variável e variada, inserida no continum das práticas, enquanto no passado era somente uma língua de elite para usos principalmente escritos, como um tipo de latim. Assim, as práticas sociais não são e nem podem ser aquelas de um francês homogêneo e único, supostamente "comum" (particularmente sob a forma de uma "norma padrão"). Isso vale igualmente, e especialmente, para todas as línguas de expansão estatal e internacional, como o inglês, o espanhol, o português. Como para toda língua, encontram-se, sobretudo, formas heterogêneas que são infinitamente renovadas segundo diferentes linhas (histórica, geográfica, social, interacional, individual, coletiva...) e que variam de acordo com as idades, o percurso educativo, os meios socioeconômicos e políticos, os sexos, as questões sociolinguísticas locais e individuais, as biografias linguageiras.

No decorrer de sua vida social, todo locutor adquire e desenvolve em permanência um conjunto de recursos linguísticos plurais que constituem seu "repertório linguístico". A comunicação linguística dos humanos não funciona sobre a base do "domínio de uma língua comum" idêntica para todos seus locutores. A diversidade e a variabilidade das práticas linguísticas não são em si obstáculos à comunicação, às relações, ao viver junto, ao contrário, elas constituem uma fonte de grande riqueza e sua ausência, ou a ausência da capacidade de se servir delas, constitui um obstáculo à comunicação e às relações humanas e sociais.

\section{Pluralidade linguística e competência sociolinguística}

Uma competência linguística é necessariamente uma competência sociolinguística (BLANCHET, 2012) para interagir, construir relações com outros, co-construir significações contextualizadas, apoiando-se sobre dois sub-saber-fazer chaves:

- a covariância (aptidão para escolher em seu reportório plural e para interpretar os 
recursos linguísticos esperados pelas normas sociais locais em função do contexto de comunicação e, mais amplamente, de relação);

- a covariação (aptidão para escolher em seu repertório plural e interpretar recursos linguísticos, mesmo os inesperados e fora do padrão, em função de uma estratégia de comunicação em um contexto preciso e, mais amplamente, de relação).

É, aliás, o sentido profundo da noção de competência plurilíngue e pluricultural (COSTE, MOORE, ZARATE, 2007), bastante difundido no mundo pelo Quadro europeu comum de referencia para as línguas do Conselho da Europa, mas muitas vezes interpretada de maneira restritiva, como se fosse relativa apenas aos padrões, ou até mesmo aos níveis de competências. Ora, essa noção insiste sobre os aspectos interliguísticos e interculturais (nomenclatura que teria sido mais explícita) heterogêneos que constituem a unidade de uma competência integrativa do conjunto de recursos linguísticos e culturais de um repertório individual plural (ou coletivo plural partilhado).

Neste quadro teórico, os signos linguísticos têm, então, um papel limitado:

- quanto mais a situação é tecnicizada, mais os sinais têm uma função semântica na construção da significação, menos o contexto tem de função significativa (mais a situação é tecnicizada, mais a língua tecnicizada, menos a interpretação é contextualizada);

- quanto mais a situação é socializada, menos os sinais têm uma função semântica na construção da significação, mais o contexto tem de função significativa (mais a situação é socializada, mais a língua é socializada, mais a interpretação é contextualizada).

Uma competência sociolinguística não é, portanto, reduzível a uma competência estreitamente linguística de codificar e decodificar uma série limitada de signos linguísticos (sons ou fonemas, palavras ou morfemas, frases ou sintagmas, textos ou discursos... segundo a terminologia empregada); ela não permite nenhuma adaptação à diversidade de contextos, interlocutores, finalidades de comunicação. Ela também não é constituída de uma justaposição de línguas estanques umas às outras (uma espécie de "plurimonolinguismo" que teria por modelo um suposto locutor nativo unilíngue), mas se constitui da tecedura de línguas e variedades integradas em uma prática de covariação e de covariância.

\section{A elaboração e o ensino exclusivo de normas padrões}

As formas retidas quando da elaboração das normas padrões, que podem ser qualificadas como artificiais (ou "fictícias" - BALIBAR, 1985) são arbitrárias (nelas mesmas, elas não são jamais, nem melhores, nem superiores a outras) e socialmente discriminantes: retêm-se, para cultivar uma distinção, as formas mais raras e as mais distantes dos usos populares / majoritários, sendo desobrigada a escolha de empréstimos de outras línguas consideradas prestigiosas e, se possível, ignoradas do comum dos mortais, como o latim ou o grego antigo no caso do francês padrão.

O francês, com efeito, é objeto de uma ideologia linguística que está entre as mais poderosas do mundo, tendo sido amplamente estudada (CALVET, 1974; CERTEAU et al., 1975 ; TRIMAILLE, ELOY, 2009; WIONET, 2011 ; BULOT, COMBES, 2012 ; BLANCHET, 2013), inclusive em seus efeitos profundos de discriminação e de insegurança sociais (BORDIEU, 1982; 2001) e, especialmente, escolares (BLANCHET, 1996 ; PRUDENT et al., 2005 ; BERTUCCI, 2013). 
Essa ideologia linguística espalhou uma crença em uma legitimidade intrínseca de uma norma linguística - na verdade de várias, pois elas são imprecisas ${ }^{5}$, apresentadas como "francês padrão [standard], legítimo, comum, bem cuidado, correto, clássico, literário, elevado, escolar etc." - que seria em si mesma, e em absoluto, melhor que as outras formas linguísticas. Não se percebe estas formas normativas como formas entre outras, arbitrariamente selecionadas e adaptadas somente a certos contextos, resultantes de escolhas politicas de hierarquização, de desigualdade e de seleção sociais. As projeções identitárias sobre as línguas foram eficazmente instrumentalizadas no momento da criação dos Estados-nações que, muitas vezes, erigiram, como na França, a língua (uma única língua sob uma única variedade normativa) em um totem sagrado de comunicação patriótica, em "religião de Estado" (CERQUIGLINI, 2003; ENCREVÉ, 2005), em "fetiche" (BOLTANSKI, BORDIEU, 1975); elas foram completadas por um tabu das outras práticas linguísticas, assim minimizadas (especialmente como "populares, rurais, locais, regionais, mestiças, imigrantes"). Todo questionamento da supremacia da norma padrão única é percebida como um sacrilégio, todo "desvio" em relação a esta suposta norma única é considerado como uma "falta" (até mesmo como um "pecado").

A adesão quase unânime a esta ideologia e a incapacidade de tomar consciência de seus aspectos eticamente chocantes (em todo caso, para aqueles e aquelas - dentre os quais numerosos professores e professoras - que têm uma ética humanista) são explicáveis pelo fato de que ela se tornou hegemônica.

\section{Poderio de uma ideologia linguística hegemônica e o papel do ensino}

Uma hegemonia (GRAMSCI, 2007'; MARCELLESI, BULOT, BLANCHET, 2003) é uma dominação da qual são impregnados os funcionamentos sociais ditos "normais", não sendo percebida como uma dominação, pois os atores sociais foram convencidos (especialmente pela escola) de que "é para o bem deles" e/ou que "isso não pode ser diferente". Eles aceitam, se apropriam e reproduzem o que eles acreditam serem evidências indiscutíveis, mesmo aqueles que, de um ponto de vista diferente, podem ser considerados como vítimas. Percebe-se, assim, como "legítima" uma "ordem das coisas" apresentada como "natural" ou "superior", da qual se dissimulam as desigualdades e as injustiças para supor que elas teriam outras causas (por exemplo, uma desigualdade "natural" ou um "fracasso individual"). Uma ideologia pode facilmente se tornar hegemônica já que é um sistema fechado de ideias a priori que tende a responder a tudo, que exige uma convicção coletiva total. Uma ideologia é, então, uma crença que filtra e organiza certa percepção/interpretação dos vividos e das ideias para impedir ou afastar toda contradição. Ela faz parte de um processo de sacralização (no sentido religioso do termo) que estabelece uma convicção de tipo religioso: tornando-se, então, uma crença, com seus totens e seus tabus, seus dogmas e seus proibidos, que só pode ser respeitada.

Para estabelecer a hegemonia desta ideologia (ou para contestá-la), são necessárias diversas alavancas de poder sobre as principais redes de produção, de difusão e de validação de conhecimentos e de discursos: escola, religião, mídia, legislação, espaços de expressão cultural, posições socioeconômicas favorizadas, funções religiosas... A escola é uma das alavancas pelas quais as ideologias são transmitidas, inculcadas, legitimadas, hegemonizadas, por isso a escola é duplamente um lugar de reprodução da ideologia linguística, não apenas porque esta ideologia é hegemônica no conjunto do corpo social (já que a escola faz parte dele), mas também porque a escola é um instrumento de manutenção das hegemonias em geral.

\footnotetext{
${ }^{5} \mathrm{E}$ deixam assim livre curso a um outro arbítrio: o dos professores.

${ }^{6}$ Esse autor lembra que esta ideologia linguística é a do Terror.
} 


\section{Pluralidade linguística e discriminações}

Discriminar significa "estabelecer uma diferença", em termos negativos, a discriminação consiste em realizar tratamentos diferentes fundados em critérios ilegítimos ou ilegais. Todo o processo de diminuição implica em um processo simultâneo, paralelo, complementar de aumento: alguma coisa passa a ser percebida como inferior em relação à outra coisa (e reciprocamente ocorre o aumento). Assim, a glotofobia implica uma glotofilia (apego muito forte a uma e, às vezes, a várias variedades linguísticas) que conduz, frequentemente, a uma verdadeira glotomania (a sobrevalorização, ou até mesmo a sacralização, de uma ou várias variedades linguísticas, línguas distintas ou forma de falar uma língua em relação a outras). E, inversamente, toda glotomania implica uma glotofobia: cada vez que se sobrevaloriza, que se reverencia uma língua ou forma de falar, outras são desvalorizadas, mesmo que implicitamente. Os discursos frequentes sobre as qualidades superiores da língua francesa reduzida a sua norma padrão (supostamente "clara", "elegante", "do pensamento", "universal") são exemplos fortes de uma glotofilia que resulta em glotomania, cuja outra face é uma glotofobia contra outras línguas ou variedades de uma língua, supostamente inferiores porque são consideradas menos claras, menos elegantes, menos capazes de exprimir um pensamento e os discursos universais (o que não tem nenhum fundamento).

O termo glotofobia é, do meu ponto de vista, preferível a discriminações linguísticas, pois ele apresenta o interesse de reinserir estas discriminações no conjunto das discriminações relativas às línguas. A glotofobia entra visivelmente na serie de alterofobias (discriminações negativas de pessoas em função da alteridade - também chamada de "diferença"), tais como a homofobia (focalizada em aspectos sexuais), a xenofobia (focalizada em aspectos identitários e culturais e frequentemente correlacionada à glotofobia), a judeofobia (ou antissemitismo) e a islamofobia (focalizadas em aspectos religiosos). Dessa forma, restitui-se às discriminações linguísticas toda sua dimensão e sua gravidade social e política, assim como sua concretização humana, e não apenas linguística. Eu defino a glotofobia como "o desprezo, o ódio, a agressão e, portanto, globalmente a rejeição, a exclusão de pessoas; a discriminação negativa efetiva ou pretensamente fundada no fato de se considerar como incorretas, inferiores ou más certas formas linguísticas (percebidas como línguas, dialetos ou usos de línguas) empregadas por estas pessoas, em geral focalizando-se nas formas linguísticas (e nunca tendo plenamente consciência da amplitude dos efeitos produzidos nas pessoas)" (BLANCHET, 2010; 2013).

A hegemonia das ideologias linguísticas glotofóbicas está tão poderosamente instalada na França que as práticas linguísticas constituem um caso quase único em que esta rejeição não é compreendida como uma alterofobia contra pessoas, mas como um tipo de avaliação "puramente" linguística, ou até mesmo objetiva e incontestável.

No entanto, as discriminações linguísticas e culturais são proibidas por numerosos textos internacionais, e especialmente europeus, que a França ratificou e que têm, portanto, força de lei nesse país. Entre eles estão: o artigo 26 do Pacto internacional relativo aos direitos civis e políticos (ONU, 1996), os artigos 2 e 28 da Convenção relativa aos Direitos da criança (ONU, 1989), o artigo 14 da Convenção europeia dos Direitos do homem e das liberdades fundamentais (Conselho da Europa, 1950) e os artigos 21 e 22 da Carta europeia dos Direitos fundamentais (União europeia, 2000, tornada vinculativa em 2007), que eu cito, a título de exemplo, porque são os mais recentes:

21. É proibida toda discriminação em razão de sexo, raça, cor, origens étnicas ou sociais, de características genéticas, língua, religião ou convicções, de opiniões politicas ou qualquer outra opinião, de pertencimento a uma minoria nacional, riqueza, nascimento, de uma deficiência, idade ou orientação sexual. 


\section{Discriminações linguísticas e insegurança linguística em educação}

A insegurança linguística é a tomada de consciência, pelos locutores, de uma distância entre o que eles falam e uma língua (ou variedade linguística) legitimada socialmente, porque ela é aquela da classe dominante, porque ela é percebida como "pura" (supostamente sem interferências de outro idioma não legítimo), ou ainda porque ela é percebida como aquela de locutores fictícios detentores DA norma veiculada pela instituição escolar (FRANCARD et coll., 1993). Como o demostrou D. de Robillard, a própria existência de uma norma padrão produz insegurança linguística em diversos níveis: "toda língua normatizada, exatamente pela existência de normas, não pode evitar de gerar nos locutores globalmente seguros uma taxa mínima de insegurança linguística" (ROBILLARD, 1996, p. 68), até mesmo nos locutores globalmente seguros de sua posição sociocultural e socioeconômica (ou nos termos bourdieusianos, detentores de um forte capital simbólico) podem engendrar dificuldades pessoais e relacionais quando o locutor está em insegurança máxima. Esta análise encontra-se em Bourdieu (1982, p. 38) que fala da "angústia que lhes faz perder todos os meios", tornando os locutores incapazes de "encontrar suas palavras", como se eles estivessem, repentinamente, "despossuídos de sua própria língua”.

Ora, a escola tem um papel particular e de grande peso na instauração da insegurança linguística "desenvolvendo ao mesmo tempo a percepção das variedades linguísticas e sua depreciação em benefício de um modelo mítico e inacessível" (FRANCARD, 1989, p.13).

\section{Propostas didáticas para uma integração da pluralidade linguística}

Numerosos trabalhos estudaram os efeitos negativos da ausência de consideração, ou até mesmo da rejeição explícita, das práticas linguísticas dos alunos, sejam elas percebidas como variante não padrão - em alguns casos "incorreta" - da língua de escolarização, ou ainda como línguas ou "não-línguas" distintas da língua de escolarização. Os estudos mostraram que esta exclusão produz "o fracasso escolar" (LAHIRE, 1993, 1999, 2008; MORO, 2002; BAUTIER, 2001, 2005, 2007; BAUTIER, RAYOU, 2009; TUPINet al., 2005; CANDELIER et al., 2008). Este fracasso é sobretudo o da escola, incapaz de realizar completamente sua missão por cegueira ideológica. Sendo ele resultado não apenas da incompreensão mútua real (ou fingida, da parte dos professores e professoras) entre aprendentes e professores, mas também da insegurança linguística dos alunos cujas produções linguageiras são estigmatizadas, com seu corolário conhecido de humilhação (MERLE, 2005), de perda de autoestima, de mutismo eletivo ${ }^{7}$, de desinvestimento, ou até mesmo de sentimento de injustiça, de indignação e de revolta (neste caso, está a famosa "violência verbal" dos alunos, percebida como tal pelos professores e professoras, mas que é, frequentemente, uma resposta à violência simbólica, cultural e verbal, que a instituição escolar e seus representantes exercem, muitas vezes, contra os alunos, especialmente naqueles que desconhecem as normas padrões dominantes da escola - cf. WIONET, no prelo ; MABILON-BONFILS, 2013 ; AUGER, ROMAIN, 2010).

Esses mesmos trabalhos propõem uma maneira recorrente de integração efetiva das práticas linguísticas dos alunos nos dispositivos didáticos e nas práticas pedagógicas. Realça-se, portanto, a distância enorme, artificial e discriminante, entre o que a escola

\footnotetext{
${ }^{7}$ O mutismo eletivo é um bloqueio que impede toda fala em uma dada situação, neste caso, na sala de aula (DAHOUM, 1995).
} 
ensina das línguas / pelas suas línguas e a maneira como as praticas sociolinguísticas funcionam e fazem sentido fora da escola. Uma língua padrão aparece, então, como uma variação entre outras, um conjunto de formas socialmente legitimadas mais ou menos precisamente definidas e empregadas, e os pretensos "erros" ou "más línguas" ou "nãolínguas" que servem para definir a norma são, normalmente, formas socialmente estigmatizadas por e para uma ideologia hegemônica.

Foi, assim, que foram desenvolvidos, avalizados e validados dispositivos nomeados de pedagogia interlinguística (CLERC, 2008; 2011) ou translinguistica (GARCÍA, 2012), muitas vezes reagrupados sob as abordagens plurais (CANDELIER, 2007), ou transposição (sócio)didática da pluralidade linguística (DABÈNE, 1994; DREYFUS, PRIEURS, 2012; FEUSSI et al., 2010; KARA, KEBBAS, DAFF, 2013). Estes trabalhos inscrevem-se justamente na passagem da noção de "domínio da língua (padrão)" àquela de "competência plurilíngue" (COSTE, MOORE, ZARATE, 1997) dando continuidade aos trabalhos mais antigos da escola de Rouen (MARCELLESI, ROMIAN, TREIGNIER, 1985) que propunham uma didática plurinormalista (da variação) em vez de simplesmente plurinormativa (das variedades) ou ainda, no pior dos casos, mononormativa (de uma norma única).

Em uma perspectiva didática, pode-se desenvolver uma análise crítica da motivação, da função e das consequências efetivas, pedagógicas, educativas, sociais e políticas, de uma língua padrão única na escola (ou na universidade). A questão glotodidática é apenas um dos aspectos de uma questão mais ampla: a do papel politico representado pela escola numa sociedade e, inversamente, a influência das forças politicas sobre os sistemas educativos e sobre o ensino-aprendizagem (incluindo o das "línguas"). Coloca-se em evidência a distância enorme, artificial e discriminante, entre o que a escola ensina das línguas/pelas línguas e de que maneira as práticas sociolinguísticas funcionam e fazem sentido fora da escola, esta constatação é, portanto, transposta na ação educativa. Uma língua padrão aparece como uma variação entre outras, um conjunto de formas socialmente legitimadas mais ou menos precisamente definidas (as divergências são numerosas sobre o que se considera como correto ou incorreto), e as pretendidas "faltas" ou "más línguas" ou "não línguas" que servem para definir a norma normalmente são apresentadas como formas socialmente estigmatizadas por e para uma ideologia politica hegemônica servindo à dominação de certas partes da sociedade sobre outras (a estigmatização e a exclusão destas formas linguísticas incidem igualmente sobre os aprendizes, os indivíduos e os grupos para quem elas são ordinárias).

Esta abordagem sociodidática (RISPAIL, BLANCHET, 2011; 2013) e as análises que ela permite conduzem a reposicionamentos em termos de intervenções didáticas: é possível definir as finalidades educativas, os objetivos da aprendizagem, os conteúdos, as modalidades e os critérios de avaliação, em termos de pluralidade. Isso permite propor práticas renovadas de ensino de "línguas", incluindo especialmente as relações que os alunos mantêm com estas línguas e suas práticas sociolinguageiras (portanto, mais amplamente sociais) fora das situações didáticas.

Dever-se-ia, dessa forma, pensar uma didática da pluralidade linguística:

- que daria um lugar central às práticas linguísticas plurais “ordinárias” necessárias à vida social e à abertura intercultural dos aprendentes, quer se trate de formas consideradas como "variedades/variações de determinada língua" (incluindo também a língua de escolarização) ou de formas consideradas como constituintes de outras línguas dos aprendentes e de seu meio;

- que poderia incluir provisoriamente formas padronizadas à condição de lhes

\footnotetext{
${ }^{8}$ No texto original, o autor usou a expressão "mauvaises langues" que, tanto em português como em francês está ligada à maledicência, mas, neste contexto, deve ser entendida como língua errada, inadequada, inapropriada.
} 
acrescentar uma historicização desta padronização para dela revelar a construção, a relatividade, as questões e os efeitos;

- que substituiria progressivamente "a" norma de uma "língua padrão", se uma politica linguística educativa de luta contra as discriminações linguísticas e de abertura à pluralidade humana e social fosse adotada (à exceção de continuar a considerar que a missão de um sistema educativo é, entre outras, a de validar e perpetuar uma ideologia glotofóbica e a hegemonia de certos grupos humanos sobre outros).

Percebe-se que o desafio é a integração da pluralidade linguística em didática das línguas, e mais amplamente, em educação, essa questão é importante e pode ser declinada em diversos graus, não somente para o sucesso dos alunos, mas também, e sobretudo, como finalidade educativa relevante de um projeto de sociedade humanista.

\section{REFERÊNCIAS}

COLLECTIF. Diversité culturelle et linguistique: quelles normes pour le francais ? Colloque, Beyrouth, Université Saint-Esprit de Kaslik, 2001. Actes en ligne : Disponível em : <www.sdl.auf.org/IMG/pdf/bey260901.pdf > . Acesso em : 12 Set. 2014.

ASSELAH-RAHAL, S. L'introduction des langues maternelles et l'apprentissage précoce en contexte algérien : pour une didactique du plurilinguisme. In : KARA, A.Y. ; KEBBAS, M.; DAFF, M. (Org.) Dynamiques plurilingues: transpositions politiques et didactiques. Cahiers de Linguistique, v.39, n.2, p. 41-48, 2013.

AUGER, N., ROMAIN, C. Malentendus interculturels et pratiques et tensions didactiques dans l'enseignement-apprentissage $\mathrm{du}$ français langue première et langue autre. In: BLANCHET, COSTE, D. (Org.). Regards critiques sur la notion d'«interculturalité». Pour une didactique de la pluralité linguistique et culturelle. Paris: L'Harmattan, 2010, p. $97-114$.

BALIBAR, R. L'Institution du français. Essai sur le colinguisme des Carolingiens à la République. Paris: PUF, 1985.

BAUTIER, É. Pratiques langagières et scolarisation. Revue francaise de pédagogie, n. 137, p. 117-161, 2001.

BAUTIER, É. Les élèves de milieux populaires et leurs pratiques langagières face aux évidences et exigences de l'école. In : BERTUCCI M.-M.; HOUDART-MEROT V. (Org.). Situations de banlieues. Enseignement, langues, cultures. Lyon: INRP, 2005.

BAUTIER, É. Langue et discours : tension, ambiguité de l'école envers les milieux populaires. Le français aujourd'hui, n 156, p. 57-66, 2007.

BAUTIER, É. ; RAYOU, P. Les Inégalités d'apprentissage: Programmes, pratiques et malentendus scolaires. Paris: PUF (2 éd. revue et augmentée 2013), 1999.

BAUTIER, E.Pratiques langagières et scolarisation. Revue Francaise de Pédagogie, n. 137, p. 117-161, 2001.

BAUTIER, E. Les élèves de milieux populaires et leurs pratiques langagières face aux 
évidences et exigences de l'école. In : BERTUCCI, M. M. Et ; HOUDART-MEROT, V. (éds). Situations de banlieues. Paris: L'Harmattan-INRP, 2005.

BAUTIER, E. Langue et discours: tension, ambiguité de l'école envers les milieux populaires. Le francais aujourd'hui, n.156, p. 57-66, 2007.

BAVOUX, C. ;PRUDENT, L.-F.; WHARTON, S. (Org.) Normes endogènes et plurilinguisme, aires francophones, aires créolophones. Lyon: ENS-éditions, 2008.

BENHOUHOU, N. Transposition des pratiques linguistiques plurielles dans les programmes de langues: quelle mise en œuvre? In: FEUSSI, V et Coll.. (Org.). Hétérogénéité sociolinguistique et didactique du français. Contextes francophones plurilingues. Cahiers de Linguistique n. 35, v. 2, 2009 [2010], p. 73-84.

BERTUCCI, M. M. (Org.). Glottopol. Revue de sociolinguistique en ligne, n. 21: Lieux de ségrégation sociale et urbaine: tensions linguistiques et didactiques ? Dysola/Université de 2013.2 Disponible sur: <www.univrouen.fr/dyalang/glottopol/numero_21.html>. Acesso em 12 Set. 2014.

BERTUCCI, M.M. ; CORBIN, C. Quel français à l'école ? Les programmes de français face à la diversité linguistique. Paris: L'Harmattan, 2004.

BLANCHET, Ph. Le métalangage des variations de langue en FLM, ou quand l'école inculque l'exclusion... Les Métalangages dans la classe de français. In: Colloque International de Didactique du Français Langue Maternelle. Actes du 6" Colloque International de Didactique du Français Langue Maternelle. Lyon: DFLM, 1996. p. 47-48.

BLANCHET, Ph. Légitimer la pluralité linguistique? Pour une didactique socialement impliquée. In: LAMBERT P.; MILLET A. ; RISPAIL M. ; TRIMAILlE C. (Org.). Variations au cœur et aux marges de la sociolinguistique. Paris: L'Harmattan, 2007. p. 207-214.

BLANCHET, Ph. Post-face en forme de coup de gueule: pour une didactique de l'hétérogénéité linguistique - contre l'idéologie de l'enseignement normatif et ses discriminations glottophobes. In : FEUSSI, V. ; EYQUEM-LEBON, M. ; MOUSSIROUMOUYAMA, A.; BLANCHET, Ph. (Org.). Cahiers de linguistique, n. 35, v.2: Hétérogénéité sociolinguistique et didactique du français. Contextes francophones plurilingues. Fernelmont (Belgique): Éditions modulaires européennes (EME), p. 165-183, 2010.

BLANCHET, Ph. La Linguistique de terrain. Méthode et théorie. Une approche ethnosociolinguistique de la complexité. Rennes: Presses universitaires de Rennes, 2012, $2^{\mathrm{e}}$ édition revue et augmentée.

BLANCHET, Ph. Standardisation linguistique, glottophobie et prise de pouvoir. In: RISPAIL, M. (Org.), Cahiers de linguistique, n 39/1: Langues et Pouvoirs. Fernelmont (Belgique): Éditions modulaires européennes (EME), p. 93-108, 2013.

BLANCHET, Ph. ; CALVET, L.-J. ; ROBILLARD, D. de. Carnets d'atelier de sociolinguistique, $\mathrm{n}^{\circ} 1$. Un siècle après le Cours de Saussure. La linguistique en question. 
Paris: L'Harmattan, 2007.

BLANCHET, Ph.; ASSELAH-RAHAL, S. (Org.). Plurilinguisme et enseignement des langues en Algérie. Rôles du français en contexte didactique. Fernelmont : EME, 2007.

BLANCHET, Ph.; MARTINEZ, P. (Org.) Pratiques innovantes du plurilinguisme, émergence et prise en compte en situations francophones. Paris: Editions des Archives Contemporaines \& AUF, 2010.

BLANCHET, Ph.; ROBILLARD, D. de (Org.) Langues, contacts, complexité. Perspectives théoriques en sociolinguistique. Cahiers de Sociolinguistique $n^{\circ} 8$. Rennes: Presses Universitaires de Rennes, 2003.

BLANCHET, Ph.; TALEB-IBRAHIMI, Kh. (Org.). Plurilinguismes et expressions francophones au Maghreb. Cahiers de Linguistique, Revue de sociolinguistique et de sociologie de la langue française $n^{\circ} 34 / 1,2009$.

BOLTANSKI, L. ; BOURDIEU, P. Le fétichisme de la langue. Actes de la recherche en sciences sociales, v. $1, \mathrm{n}^{\circ}$ 4, p. 2-32, 1975.

BOURDIEU, P. Ce que parler veut dire, l'économie des échanges linguistiques. Paris: Fayard, 1982.

BOURDIEU, P. Langage et pouvoir symbolique. Paris: Seuil, 2001.

BULOT, Th. ; COMBES, N. (Org.) Discriminations, identités, altérité, langues. Paris: L'Harmattan, 2012.

CAITUCOLI, C. (Org.). Situations d'hétérogénéité linguistique en milieu scolaire. Rouen: Presses de l'université de Rouen, 2003.

CALVET L.J. Linguistique et colonialisme. Petit traité de glottophagie. Paris: Payot, 1974, dernière éd. 2002.

CALVET L.-J. Essais de linguistique. La langue est-elle une invention des linguistes? Paris: Plon, 2004.

CANDELIER, M. (Org.) Cadre de référence pour les approches plurielles des langues et des cultures. Strasbourg/Graz, Conseil de l'Europe/Centre européen pour les langues vivantes, 2007. Disponible sur $:<<$ http://carap.ecml.at/ $>>$. Acesso em $: 12$ Set. 2014.

CANDELIER, M. et al. (Org.). Conscience du plurilinguisme. Pratiques, représentations et interventions. Rennes: Presses universitaires de Rennes, 2008.

CASTELLOT'TI, V. La langue maternelle en classe de langue étrangère. Paris: Clé International, 2001a.

CASTELLOT'TI, V. (Org.). D'une langue à d'autres: pratiques et représentations. Rouen: Publications de l'Université de Rouen, 2001b.

CERQUIGLINI, B. Le français, religion d'Etat ? Le Monde du 26 novembre 2003. 
CERTEAU, M. ; JULIA, D.; REVEL, J. Une politique de la langue. La Révolution française et les patois. Paris: Gallimard, 1975..

CHAUDENSON, R. Education et langues: Français, créoles, langues africaines. Paris: L'Harmattan / OIF, 2006.

CLERC, S. Les langues-cultures. Pour des approches interlinguistiques des langues des élèves nouvellement arrivés en France. Diversité, n. 153, Le principe d'hospitalité, p. 171176, 2008.

CLERC, S. Vers une didactique de la pluralité sociolinguistique. Synthèse d'HDR, Université de Provence, 2011.

CLERC, S.; CORTIER, C. De l'analyse des pratiques langagières et des représentations des langues chez des élèves plurilingues à leur prise en compte dans l'espace scolaire. In : CANDELIER, M. et coll.. Conscience du plurilinguisme. Pratiques, représentations et interventions. Rennes: PUR, p.151-165, 2008.

CLERC, S.; MANCHET-RICHERME, C. La recherche-action-formation : une stratégie glottopolitique en terrain scolaire. In: COLONNA R. (Org.). Actes du Colloque du Réseau francophone de sociolinguistique de Corte (2013). No prelo.

COLONNA, R. ; BECETTI, A. ; BLANCHET, Ph. (Org.) Politiques linguistiques et plurilinguismes: du terrain à l'action glottopolitique. Paris: L'Harmattan, 2013.

COSTE, D. (Org.) Les langues au cœur de l'éducation. Fernelmont: EME/ADEB, 2013.

COSTE, D. ; MOORE, D. ; ZARATE, G. Compétence plurilingue et pluriculturelle. Strasbourg: Conseil de l'Europe, 1997.

DABENE L. Repères sociolinguistiques pour l'enseignement des langues. Hachette: Paris, 1994.

DAHLET, P. Le plurilinguisme sur un baril de poudre : splendeur d'un idéal et violences des pratiques. In: BLANCHET, Ph. ; CHARDENET, P. (Org.), Guide pour la recherche en didactique des langues et des cultures. Approches contextualisées. Montréal / Paris: Agence Universitaire de la Francophonie / Editions des Archives Contemporaines, p. 4560, 2011.

DAHOUN, K. S. Z. Les Couleurs du silence: Le mutisme des enfants de migrants. Paris: Calman-Lévy, 1995.

DREYFUS, M. ; PRIEUR, J. M. (Org.). Hétérogénéité et variation. Perspectives sociolinguistiques, didactiques et anthropologiques. Paris: M. Houdiard éditeur, 2012.

ENCREVE, P. Les droits linguistiques de l'homme et du citoyen. Conférence à l'EHESS, 2005. Disponible sur:< http://www.langues-de-france.org/encreve.html $>$. Acesso em: 12 Set. 2014. 
FEUSSI, V... et al.. (Org.). Hétérogénéité sociolinguistique et didactique du français. Contextes francophones plurilingues. Cahiers de linguistique, n. 35, v.2. Fernelmont (Belgique): Éditions modulaires européennes (EME), 2010.

FRANCARD, M. (Org.). L'insécurité linguistique dans les communautés francophones périphériques. Cahiers de l'Institut de Linguistique de Louvain, n.19, v.3-4, 1993.

FRANCARD, M. Insécurité linguistique en situation de diglossie. Le cas des Ardennes belges. Revue québécoise de linguistique théorique et appliquée, n. 8, v.2, p. 133-163, 1989.

GARCÍA, O. Theorizing translanguaging for educators. In: CELIC, C.; SELTZER, K. Translanguaging: A CUNY-NYSIEB guide for educators, p. 1-6, 2012.

GRAMSCI, A. Quaderni del carcere, a cura di V. Gerratana, 4. v., Torin: Einaudi, 2007 $[1975,1948]$.

KARA, A.Y.; KEBBAS, M. ; DAFF, M. (Org.) Dynamiques plurilingues : transpositions politiques et didactiques. Cahiers de linguistique, $n^{\circ} 39 / 2$. Fernelmont (Belgique): Éditions modulaires européennes (EME), 2013.

LAHIRE, B. Culture écrite et inégalités scolaires. Sociologie de l'« échec scolaire » à l'école primaire. $2^{\mathrm{e}}$ éd. Lyon: PUL, 1993. 2000.

LAHIRE, B. L'invention de l'« illettrisme » : Rhétorique publique, éthique et stigmates. $2^{\mathrm{e} e}$ éd. Paris: La Découverte, 1999, 2005.

LAHIRE, B. La Raison scolaire. École et pratiques d'écriture, entre savoir et pouvoir. Rennes: Presses universitaires de Rennes, 2008.

LÜDI, G. ;PY, B. Etre bilingue. Berne: Peter Lang, 1986.

MAÏGA, A. (Coord.). Le français dans les aires créolophones. Vers une didactique adaptée. Paris: OIF / L'Harmattan, 2007.

MARCELLESI, Ch.; ROMIAN, H. ; TREIGNIER, J. Quelques concepts et notions opératoires pour une pédagogie de la variation langagière. Repères, n. 67 'Ils parlent autrement.' Pour une pédagogie de la variation langagière, p. 23-31, 1985.

MARCELLESI, J. B.; BULOT, T.; BLANCHET, Ph. Sociolinguistique (épistémologie, langues régionales, polynomie). Textes choisis de Jean-Baptiste Marcellesi précédés d'un entretien. Paris, L'Harmattan, 2003.

MAURER, B. De la pédagogie convergente à la didactique intégrée: langues africaines-langue française. Paris : L'Harmattan, 2007.

MAURER, B. Les langues de scolarisation en Afrique francophone, rapport de recherche AUF, $2010 . \quad$ Disponible sur $<$ http://www.bibliotheque.auf.org/doc_num.php?explnum_id=268.

MERLE, P.L'élève humilié. L'école un espace de non droit ? Paris : PUF, 2005. 
MORO, M. R. Enfants d'ici venus d'ailleurs. Naître et grandir en France. Paris : La Découverte, 2002. Edition Pluriel en 2011.

OMER, D.; TUPIN, F. (Org.) Educations plurilingues. L'aire francophone entre héritages et innovations. Rennes : PUR, 2013.

PRUDENT, L. F.; TUPIN, F.; WHARTON, S. (éd) Du plurilinguisme à l'école. Vers une gestion coordonnée des langues en contextes éducatifs sensibles. Bern: Peter Lang, 2005.

RISPAIL, M. ; BLANCHET, Ph. Principes transversaux pour une sociodidactique dite de terrain. In : BLANCHET, Ph.; CHARDENET, P. (Org.), Guide pour la recherche en didactique des langues et des cultures. Approches contextualisées. Montréal; Paris: Agence universitaire de la francophonie / Éditions des Archives contemporaines, 2011. p. 65-69.

RISPAIL, M. ; BLANCHET, Ph.Contextualisación de las investigaciones y acciones : en pro de unaperspectivasociodidáctica. In: RAMÍREZ ROMERO, J. L., (Coord.). Une década de búsqueda: las investigaciones sobre la enseñanza y el aprendizage de lenguasextranjeras en México (2000-2011). México: Pearson Educación, 2013. p. 317-325.

ROBILLARD, D. de. Le concept d'insécurité linguistique: à la recherche d'un mode d'emploi. Français régionaux et insécurité linguistique. Paris: L’Harmattan / Université de la Réunion, 1996. p. 55-76.

ROBILLARD, D. de. Perspectives alterlinguistiques. Paris: L’Harmattan, 2008. v.2.

ROBILLARD, D. de ; BENIAMINO, M. (Org.). Le français dans l'espace francophone. Paris: Champion, 1993, 1995, nouvelle éd. 2010. (2 vol.)

ROMIAN, H. (Org.) Didactique du français et recherche-action. Paris: INRP, 1989.

WIONET, C. La langue commune: questions critiques. In: BRANCA-ROSOFF S. ; FOURNIER J. M.; GRINSHPUN Y.; RÉGENT-SUSINI A. (Org.). Langue commune et changements de normes. Paris: Champion, 2011. p. 135-145.

WIONET, C. Violence verbale, violence pour qui ? Colloque La peur des mots : mots censurés et autocensurés. Brest, n.29, v.30 avril 2010. No prelo.

Recebido em 09/06/2014

Aprovado em 04/11/2014 